\title{
Systems engineering fundamentals of state construction supervision structure in reshaping of large city territories
}

\author{
Dmitry Topchiy ${ }^{1, *}$ and Andrey Tokarskiy ${ }^{1}$ \\ ${ }^{1}$ Moscow State University of Civil Engineering (NRU MGSU), Moscow, Russia
}

\begin{abstract}
The article describes the significance of the Developer's (Technical Customer) construction compliance control mechanism as an effective tool of reducing potential risks in investment and construction projects. It contains a general description of the practice of attracting organizations to conduct construction monitoring, a need for an integrated, systematic approach to the process of work acceptance. The proposed scheme of the comprehensive verification control including the laboratory validation of the Contractor's data for the purpose of optimization and improvement of control functions was analysed using existing statistical methods. There have been indicated ways of determining qualitative and quantitative characteristics of the sample (verification control) from the universe common array (the source control of the Contractor) in compliance with the representativeness terms.
\end{abstract}

\section{Introduction}

Almost any complex system can be represented by a structure with a dynamic interaction between elements of the "built" environment (material objects), the human factor and environmental influence.

The Building Production System refers to such complex systems and is designed for the formation of construction products for various functional appointments. The end result of the Building Production System functioning is a completed facility, that is, a building or structure of a definite purpose and present quality which becomes the main indicator of its functional efficiency [1].

In a number of reviewed foreign countries, Customers of building products practice the operation of the Construction Supervision Service in one form or another, despite the fact that its necessity is not everywhere regulated by the legislation (Table 1). In addition, modern legislation, both in Russia and globally, does not require from the Construction Supervision Service to conduct random instrumental, geodetic measurements and, especially, verification laboratory support of construction in the course of its control activities. Given that the construction compliance monitoring undertaken by the Customer should include checking the correctness, completeness and compliance with the deadline established by the Contractor of the input control and the reliability of documenting of its results, meeting these requirements is virtually impossible due to non-transparent schemes of many studies and tests performed at the construction site.
Table 1. Practice of the Customer's Construction Supervision Service operation in some foreign countries

\begin{tabular}{|l|l|l|}
\hline No. & \multicolumn{1}{|c|}{ Country } & $\begin{array}{l}\text { Summary of construction } \\
\text { supervision approach specifics on } \\
\text { behalf of the Customer }\end{array}$ \\
\hline 1 & $\begin{array}{l}\text { Russian } \\
\text { Federation }\end{array}$ & $\begin{array}{l}\text { Internal or external construction } \\
\text { supervision service[2] }\end{array}$ \\
\hline 2 & Belarus & $\begin{array}{l}\text { Internal or external construction } \\
\text { supervision service[3] }\end{array}$ \\
\hline 3 & $\begin{array}{l}\text { United } \\
\text { Kingdom }\end{array}$ & $\begin{array}{l}\text { Written assurance of the General } \\
\text { contractor on the application of } \\
\text { an effective system of quality } \\
\text { control of products with the } \\
\text { appointment of a quality } \\
\text { manager. Contractors' self- } \\
\text { certification system is in } \\
\text { practice[4] }\end{array}$ \\
\hline 4 & Germany & $\begin{array}{l}\text { Quality assurance system, } \\
\text { Qualitatssicherungs system } \\
\text { (QSS), the key principle of which } \\
\text { is 'to produce quality not to } \\
\text { monitor it" [5] }\end{array}$ \\
\hline 7 & New Zealand & $\begin{array}{l}\text { There is no construction } \\
\text { supervision service as such. } \\
\text { An external expert is usually } \\
\text { invited to assess the quality of } \\
\text { finished construction facilities[6]. }\end{array}$ \\
\hline 5 & Sweden & $\begin{array}{l}\text { The construction supervision on } \\
\text { behalf of the Customer is } \\
\text { voluntary [7] }\end{array}$ \\
\hline The construction supervision on \\
\hline 6
\end{tabular}

\footnotetext{
* Corresponding author: $\underline{89161122142 @ \text { mail.ru }}$
} 


\begin{tabular}{|l|l|l|}
\hline No. & Country & $\begin{array}{l}\text { Summary of construction } \\
\text { supervision approach specifics on } \\
\text { behalf of the Customer }\end{array}$ \\
\hline 8 & USA & $\begin{array}{l}\text { behalf of the Customer is } \\
\text { voluntary[8]. }\end{array}$ \\
\hline $\begin{array}{l}\text { The construction supervision on } \\
\text { veluntary. } \\
\text { The customer is responsible for } \\
\text { the constructed facilities during } \\
\text { the whole period of } \\
\text { maintenance[9] }\end{array}$ \\
\hline
\end{tabular}

\section{Germany}

Qualitätssicherungssystem is a quality assurance system in Germany that operates in all house-building plants. Its main requirement is to create high-quality products, instead of controlling the quality of the work already done. In the result of joint work of the quality Department of the plant with the state construction Inspectorate and close interaction with production teams on the ground to build a solid base to eliminate factors of occurrence of marriage.

The regulatory framework of the quality assurance system is made up of DIN EN ISO 9000, 9001 standards, developed by ISO and the European Commission for standardization CEN, and the main working document is the action plan for quality assurance, which is made for the entire construction period. In the production every month the analysis of the state of Affairs on the quality of construction in order to identify the causes of defects and alterations, organized and ensured the quality control system to construction and installation work in accordance with international norms and standards. This system enables the contractor to monitor the implementation of the project at any time and to intervene to eliminate defects and miscalculations if necessary.

\section{Finland}

The quality of construction in Finland is guaranteed, first of all, by compliance with the General requirements of the Finnish construction legislation (SFN-EN ISO 9000; 9001), as well as with the contract with the contractor, which specifies all the terms and obligations. The warranty period of the contract, according to the legislation of Finland, is 24 months from the date of acceptance of all contract works. The law on land use and construction, Maankäyttö-ja rakennuslaki, obliges the developer to provide the necessary conditions for construction. The so-called "building information cards", RT-cards, (RT-kortti, which are issued by a non - profit organization-the Association of the construction industry of Finland) give the concept of "good construction practice", which provides for compliance with the requirements of the authorities, the use of appropriate materials, consideration of the environmental aspect, high quality work, etc.

\section{Japan}

Quality management in Japan is based on the following fundamental statements:
1. Eliminating not the defects themselves, but their root causes. This is quite time-consuming but can give dramatic results.

2. In quality management there is an emphasis on the interest of the contractor.

3. Independence in the choice of means and methods, forming the basis for collective action.

A large public institution for quality in Japan is the Japanese Union of engineers and scientists. The key activities of this institution are: research in the field of product quality management, training and professional development of employees, advocacy and printing. The specialists of this Association carry out a survey of candidate companies for the Deming prize. This award was established in Japan in 1951 in honor of Edwards Deming, one of the main experts of the United States on the introduction of statistical methods of quality control. Deming's remuneration can be awarded to individual specialists for abstract research of statistical methods of control, as well as to companies for their actual use.

\section{Britain}

In the United Kingdom, the standards Institute has established and operates a quality-tested company registration system. The objective of the system is to provide, through systematic evaluation and supervision, assurance that a company with an appropriate certificate can perform work at the appropriate level (i.e., quality system certification). The main condition of certification is the existence of the company's effective quality control system.

The British Institute of standards (BSI) was founded in 1901 on the initiative of the communities of shipbuilding engineers, metallurgists, mechanical engineers and electrical engineers. The key functions of BSI are to coordinate the development of standards on the basis of a contract among absolutely all stakeholders and the approval of standards. The main Executive body of BSI-the steering Committee, accountable to the General conference, manages the work of the Institute and controls all activities. BSI consists of group and individual members (over 15 thousand members). companies, institutions and individuals) interested in participating in the standardization and use of standards.

The main working bodies of BSI-technical committees (there are about 3 thousand) - directly develop national standards. The standardization committees are responsible for this work, which in turn report to the industry standardization councils. Representing manufacturers, consumers and all other stakeholders in a particular area is the main objective of industry councils.

The total number of functioning state standards reaches 20 thousand. The Central reference service provides information on standardization and dissemination of data on standards. This service has an automated data system "Standard-line", which is made with the participation of the British Institute of standards.

In addition to standardization, BSI leads quality management and certification activities. Problems of quality and certification is managed by the Council for quality assurance, reporting to the governing Council. 
The BSI has a large enough experimental center, which performs tests of a wide range of serial product. Tests are carried out both for suitability to safety requirements and for compliance of the product with national standards. The BSI center is one of the most authoritative in the world, and almost all States recognize its certificates of conformity without secondary testing.

\section{USA}

In the United States, quality management in the late 1970s was limited to quality planning, and this was the prerogative of the quality service. At the same time, quite little attention was paid to in-house buyers, the intentions of increasing the quality were made in the absence of taking into account the needs within the company. This quality management process created only problems, not plans.

Us experts have high hopes for the development of quality management, which means, in their opinion, an effective restructuring of management consciousness, a radical change in corporate culture and a stable mobilization of forces at all levels of the organization to find ways to constantly increase the quality of American products.

The normative documents are Building Codes ("Building codes") and Standards ("Standards"). The concept of the latter includes all types of regulatory documents used to determine the required qualities of buildings, structures, products of the construction industry and scientific and technical processes of construction. In any case, standards, in fact, provide perhaps the most important thing - the understanding between the consumer and the manufacturer. They are focused on the protection of human health and safety [11].

Systematic quality control (the so - called "do-it-first" concept) is a significant principle that ensures the leading position of American companies in the global economy. In accordance with this concept, quality is ensured by introducing quality responsibility in each job description or job description of the production worker.

\section{Materials and methods}

The concept of the Building Production System involves the appliance of methods and techniques of system analysis for assessment, organisation and management of production and non-production processes of interaction between structural elements of the system. This system analysis is characterised by the following features:

- A systematic approach is used to analyse systems only;

- Necessity of a hierarchical approach and multi-level (iterative) nature of the study object analysis;

- Integration mechanism analysis and influence of structural elements in the set of elements and structural complexes on outcomes of the system functioning;

- Focus of the researches on obtaining quantitative characteristics determining the system behaviour or condition.
In adopted formulation of analysis the Building Production System is considered as a complex, polyergatic and hierarchical system consisting of a combination of less complex sub-systems (systems and elements). Each of these sub-systems can be considered as an independent study subject[10].

The main features of the Building Production System concept as a complex polyergatic system are shown in Table 2.

Table 2. The main features of a polyergatic system

\begin{tabular}{|c|c|}
\hline $\begin{array}{l}\text { Types of } \\
\text { system feature }\end{array}$ & $\begin{array}{l}\text { Quality characteristics of system } \\
\text { feature }\end{array}$ \\
\hline Functional & 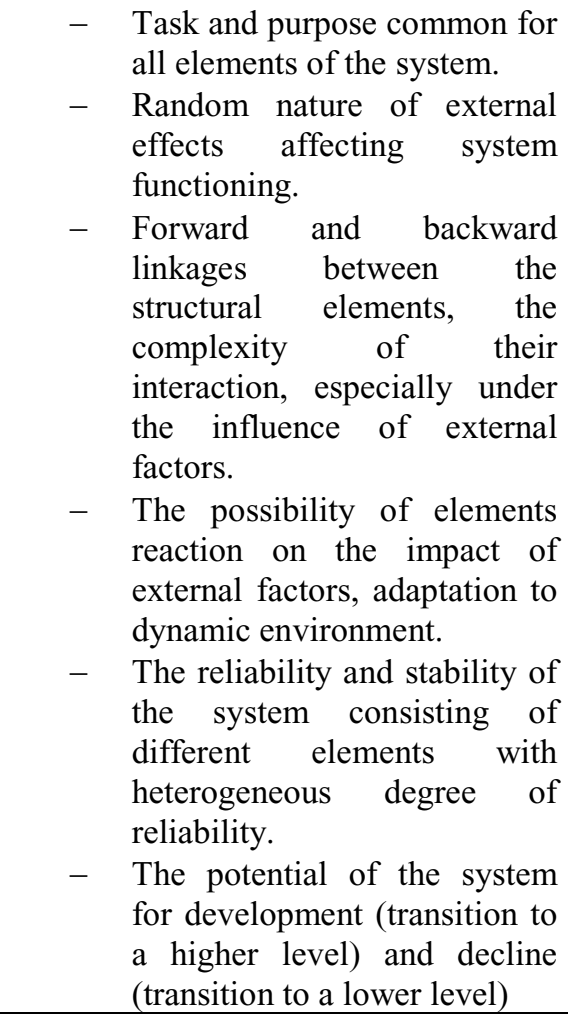 \\
\hline Structural & $\begin{array}{l}\text { - A significant number of the } \\
\text { structural elements } \\
\text { constituting the system. } \\
\text { - The possibility of combining } \\
\text { in groups (sub-systems) of } \\
\text { elements according to some } \\
\text { established features. } \\
\text { - A hierarchical structure and } \\
\text { criteria of functioning. } \\
\text { - Dynamism of conditions and } \\
\text { relations }\end{array}$ \\
\hline Ergonomic & $\begin{array}{l}\text { - The subjective nature of } \\
\text { solutions. } \\
\text { - The possibility of accidental } \\
\text { and intentional errors. } \\
\text { - The unpredictability of } \\
\text { productivity, behaviour and } \\
\text { moods, inability to predict the } \\
\text { results taken for } \\
\text { implementation of the } \\
\text { solutions }\end{array}$ \\
\hline
\end{tabular}


The considered method of state construction supervision for capital construction projects subject to state construction supervision is divided into three categories of risk: high, significant and moderate risk [12].

The criteria for classifying the objects of state supervision to a certain category, the maximum number of inspections for the period of construction or reconstruction of the object for each category of risk. The grounds for increasing the limit number of inspections for each risk category are also determined.

Risk categories of capital construction projects under construction and reconstruction subject to state supervision are established on the basis of [13]:

- Severity of potential negative consequences of possible non-compliance with mandatory requirements during construction and reconstruction of construction facilities;

- Identification signs of objects of capital construction according to points 1 and 2 of part 1 of article 4 of the Federal law of December 30, 2009 No. 384-FZ "Technical regulations on safety of buildings and constructions" (purpose of object of capital construction, belonging to objects of transport infrastructure and to other objects which functional and technological features influence their safety);

- Functional purpose of capital construction projects, determined in accordance with national standards and codes of practice.

The use of this method will improve the efficiency of control and supervision during the state construction supervision with the optimal use of material, financial and human resources of the state control bodies, improve the quality of construction and reconstruction of capital construction, encourage persons involved in the construction and reconstruction of capital construction, to prevent disruption of construction time. At the same time, the main functioning feature of the Building Production System as polyergatic system is a constantly growing discrepancy between the technical characteristics and technological capabilities, that is, building machines and mechanical aids intended for creation of major construction building systems, and organizational and technological reliability aimed at ensuring the preset quality level of construction products at the construction phase[14].

Engineering approach to the functioning analysis of the united and integrated Building Production System involves analysis of interaction terms between technical, organizational, managerial and structural elements oriented towards ensuring the established quality level of construction products.

State construction supervision is carried out in the Russian Federation in accordance with the Decree of the Government of the Russian Federation of February 1, 2006 № 54 "on state construction supervision", which spelled out "Regulations on the implementation of state construction supervision in the Russian Federation". This Regulation establishes the order of implementation of the state construction supervision in the Russian Federation. State construction supervision is carried out: a) in the construction of capital construction projects, if the project documentation for their construction is subject to state examination in accordance with article 49 of the town-Planning code of the Russian Federation or is a standard project documentation or its modification, which received a positive conclusion of the state examination; b) at reconstruction, capital repairs of objects of capital construction if project documentation on implementation of reconstruction, capital repairs of objects of capital construction is subject to the state examination according to article 49 of the town-Planning code of the Russian Federation. The task of the state construction supervision is the prevention, detection and suppression of admitted by the developer, the customer, as well as the person carrying out construction on the basis of the contract with the developer or the customer (hereinafter - the contractor), violations of the legislation on urban development, including technical regulations, and project documentation. The subject of state construction supervision is the verification of: a) compliance of works and construction materials used in the construction, reconstruction, overhaul of capital construction, as well as the results of such works to the requirements of technical regulations, other regulations and project documentation; b) the presence of a construction permit; C) compliance with the requirements of parts 2 and 3 of article 52 of the town Planning code of the Russian Federation[15].

In case of absence of technical regulations the subject of the state construction supervision is the verification of compliance of the performed works, the applied construction materials and results of such works to construction norms and rules, Federal norms and rules in the field of use of nuclear energy, sanitary and epidemiological rules and standards, requirements of fire safety, requirements in the field of environmental protection, requirements of the state protection of cultural heritage and requirements for the preservation of cultural heritage, norms and rules of engineering and technical measures of civil defense, requirements of industrial safety, norms and rules of safety of hydraulic structures, other safety rules and state standards, as well as the requirements of other regulatory legal acts of the Russian Federation and regulatory legal acts of Federal Executive authorities, subject to mandatory execution in the construction, reconstruction, overhaul of capital construction projects (hereinafter-the rules and regulations). State construction supervision is carried out by Federal Executive authorities authorized to carry out state construction supervision, and Executive authorities of the subjects of the Russian Federation authorized to carry out state construction supervision. If at construction, reconstruction, capital repairs of capital construction objects implementation of the state construction supervision is provided, body of the state construction supervision within

The State Construction Supervision system is (in the vast majority of cases) mandatory and necessary structural element (sub-system) of the united and integrated Building Production System.

The considered structural element is designed to perform the oversight functions necessary to ensure the 
established level of quality, safety and timeliness of creation of capital construction building systems.

Figure 1 demonstrates the scheme of interaction of the State Construction Supervision system (sub-system) with the main structural elements of the Building Production System[16].

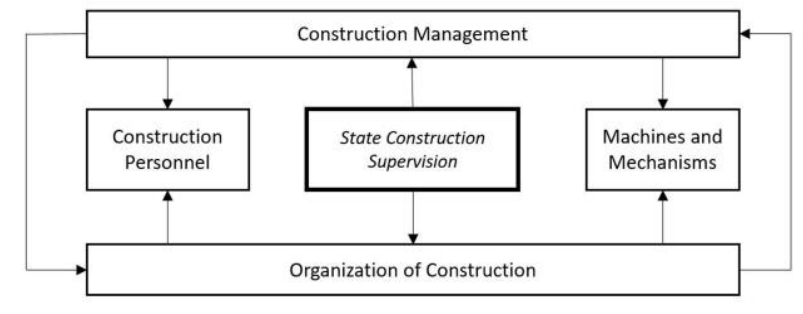

Fig. 1. The scheme of interaction of the State Construction Supervision system (sub-system) with the main structural elements of the Building Production System

The State Construction Supervision system (subsystem) is interconnected with "Construction Management" and "Organisation of Construction" systems (sub-systems) of the united and integrated Building Production System. Control actions of the State Construction Supervision system (sub-system) are implemented by construction personnel including operators of building machines and mechanisms.

The performance of the State Construction Supervision system (sub-system) is defined by: training and labour discipline of the personnel; the rational organisation of the internal structure of the service; the quality of interaction with external (organisational, managerial, expert) structures.

The use of system analysis methodology seems a rational way to determine the features of the State Construction Supervision system (sub-system) functioning mechanism as a complex, evolving (taking into account the life cycle period of the major construction object) and multi-level hierarchical organisation [17].

According to system analysis, it is required that the tasks set for the State Monitoring of Construction Products Quality Assurance Institute (system, subsystem) are reviewed and solved in the context of the modern Building Production System functioning performance, as a result of interaction of various construction investment entities.

The causes of different problem situations (technical, organisational, managerial, economic, legal, social) related to structural peculiarities of The Building Production System (as a united and integrated system, or supersystem) and the State Construction Supervision system (as a sub-system) can be studied using Systems Engineering principles to increase functioning performance of these systems. The Systems Engineering principles are the following[18]:

- Functional-system principle: is the formation of a specific result in the form of construction products of established quality level (main purpose of functioning of the system). To achieve the required specific result, the necessary manufacturing relations (ways of interactions) between the hierarchically organised functional systems are formed. In the great majority of cases, functional systems consist of heterogeneous elements, each of which is characterised by individual specific weight (importance) determining the impact on achieving the end result by the entire system. Assessment of the final result displaying adequacy for each of the structural systems (sub-systems) included in the united and integrated system (a supersystem) is produced using methods of the functional systems theory[19];

- Statistical-probability principle: is one of the basic modern types (concepts) of scientific worldview in relation to the study subjects. A probabilistic (statistical or statistical probability) approach is based on the picture of the distributions which mediates the relations between the properties of the system structural elements. Modern technical, economic, organisational, sociological, organisationaltechnological and managerial systems are characterised by a certain level of reliability that is being significantly reduced in accordance with the growing complexity of systems. Therefore, the exact methods of calculating major construction reliability and quality indicators are of paramount practical importance. The use of calculation (computational) probabilistic and statistical methods of study of random processes and phenomena distribution laws is fully justified approach in engineering calculations for determining of the quantitative indicators of construction reliability [20];

- Simulation-modelling principle: A wide spread of various methods of determining (modelling) the characteristics of the corresponding objective function for the rational solution of practical problems is characterised by the following factors: development and complication of various structural and building systems of major construction projects; various types of buildings and structures functional use; the conditions of production of technological processes; climatic and hydrogeological conditions of the construction objects area; the random nature of application and operative conditions. The mathematical model allows for the analysis of processes development in space and time in strict accordance with specific conditions where the real object of research is. It is especially important if the possibility of the formulation and conduct of physical (natural) experiment does not exist[21];

- Interactive-graphics principle: the use of electronic computing machines (ECM, subject to availability of proper software) for defining the calculated parameters of analytical (mathematical) models of building and calculation graphic interpretations allows: to increase significantly the efficiency of data and indicators obtaining; to achieve a high rate of teams work efficiency; to optimise design and management solutions; to provide a compact and informative presentation of data (documentation chapters). User-friendly interaction of a projecting engineer and ECM is the most common form of 
rational combination of intellectual and professional skills and knowledge of the projecting engineer and the mathematical methods of analysis, as well as software and hardware tools for their implementation.

- Human-engineering principle: Design of Building Production organisation and management (the Building Production System functioning) is characterised by large dimension amplitude, complex formalisation of relationship between separate structural elements, dynamic nature of the parameters characterising construction procedures. Some problems cannot be fully formalised due to their multicriteriality and lack of proper mathematical tool or efficient numerical computation. Therefore, nonformalisable or hard-to-formalise problems should be solved by human (engineer, technician, operator, decision maker). Human engineering awareness is an important methodological factor affecting the organisation of graphic (multi-dimensional) data presentation. Allocation of functions for optimising of interaction between human and computing machine within a single system of "ECM (machine) $\leftrightarrow$ human (operator)" type [22].

- Engineering-economy principle: provides an opportunity of operational evaluation of design, planning, organisational, managerial solutions involving information models that provide opportunities to receive feedback. This methodological principle defines the development of reliable formalised and normalised assessment procedures as a means of economic study of solution quality and efficiency. Development of objectoriented models designed to solve specific problems of economic appraisal is a promising and rational way to enhance the efficiency of design solutions in the context of traditional posteriori Quality Assessment System for completed facility. It is essential when similar functionalities are absent or require a significant investment of labour in their application.

\section{Results and discussion}

The analysis of features of the State Construction Supervision system (sub system) functioning allows the use of a random number of considered Systems Engineering principles (or their combinations) coupled with the more specific (inherent in organisational systems) forms and methods of system analysis based on the concepts of the General Systems Theory.

The need for systems engineering approach to the analysis of organisational-technical (complex) structure functioning became clear after emerging of situations when single and well-functioning elements (subsystems) combined through a particular interaction were not a well-functioning system[23].

In a complex system (sub-system) it often turns out that the correction of the decision (or its adaptation to the actual conditions of the construction site) requires much higher cost than the remuneration of the State Construction Supervision system (sub-system) professional and technical units. For this reason, the process of "monitoring" of the major construction object should begin in the earliest periods of the life cycle.

Increasing complexity of functional stress affecting the State Construction Supervision system (sub-system) is an inevitable consequence of such approach. It includes the use of aids and results of simulation and experimental modelling oriented towards the system analysis of Construction Products Quality Assurance methods, that is, system concepts of use of modern scientific and technological development.

In the great majority of cases, the decision-making must be implemented in terms of the best possible capture of various investment entities involved in construction. The explicit and implicit connections between them and the environment (both "built" and natural) are the union of two major conceptual methodological approaches: "a part $\leftrightarrow$ a whole" and "a system $\leftrightarrow$ an environment”.

\section{References}

1. A. Lapidus., I Abramov, Formation of production structural units within a construction company using the systemic integrated method when implementing high-rise development projects, A. Lapidus, I. Abramov, E3S Web of Conferences, No. 33. (2018)

2. A. Lapidus, A. Makarov, Formation of production structural units within a construction company using the systemic integrated method when implementing high-rise development projects, A. Lapidus, A. Makarov, MATEC Web Conf. No. 86. (2016)

3. P. Oleinik, Method for creating a work management plan of a construction company, Oleinik P., International Journal of Construction Management. No. 7. (2017)

4. P. Oleinik. Methods of erection of high-rise buildings, Oleinik P., E3S Web of Conferences, No. 33. (2018)

5. S. Sinenko, A. Slavina, Performance indices of project companies virtual divisions in the construction in CAD conditions, S. Sinenko, A. Slavina, MATEC Web Conf., No. 106. (2017)

6. GOST R ISO, IEC TO 16326-2002. Software engineering. Guidance on the application of GOST $R I S O$, IEC 12207 in project management (see ISO , IEC 16326). M $\therefore$ IPK Publishing House of Standards (2002)

7. D. Topchiy, V. Skakalov, A. Yurgaitis A, Integrated verification construction supervision as a tool to reduce the developer's risks when implementing new and redevelopment projects, International Journal of Civil Engineering \& Technology (IJCIET) Volume 9, Issue 1, (Jan 2018), pp. 85-993. (2018)

8. A. Kosyakov, U. Svit, S. Seymour, S. Beamer, System Engineering. Principles and practice, Translated from English by V. Batovrin. Moscow: DMK Press- 636 p. (2014) 
9. I. Abramov, T. Poznakhirko, A. Sergeev, The analysis of the functionality of modern systems, methods and scheduling tools, I. Abramov, T. Poznakhirko, A. Sergeev, MATECWebConf. No. 86 (2016)

10. D. Topchiy, E. Kochurina, Estimation of the degree of influence of environmental factors on construction in a dense urban environment, D. Topchy, E. Kochurina, System technologies, No. 1 [26], - p. 107-111 (2018)

11. ISO/IEC 29110: 2011 Systems Engineering Standards for Very Small Entities. -9 p.

12. The official website of the building complex of Moscow, Complex of town-planning policy and construction of the city of Moscow, URL: https://stroi.mos.ru/ (circulation date April 10, 2018).

13. D. Topchiy, V. Efremova, Formation of information support in the re-development of industrial territories, D. Topchiy, V. Efremova V., Innovations and Investments. - 2018. - No. 3, p. 265-268.

14. D. Topchiy. V. Skakalov, Structural and functional modeling of multi-level and multi-criteria links of organizational and technological, managerial structures and information support when implementing construction control over the course of re-development of industrial facilities, D. Topchiy, V. Skakalov, Prospects of science. 2017. - No. 10 (97) - P. 44-50.

15. A. Lapidus, I. Abramov, E3S Web of Conferences, 33, 170 (2018)

16. A. Lapidus, A. Makarov, MATEC Web Conf, 86, 79 (2016)

17. P. Oleinik, IJCM, 7, 34 (2017)

18. P. Oleinik, E3S Web of Conferences, 33, 89 (2018)

19. S. Sinenko, A. Slavina, MATEC Web Conf, 106, 153 (2017)

20. M.J. Billington, The building regulations (Blackwell publishing, 2007)

21. D. Topchiy, V. Skakalov, A. Yurgaitis, IJCIET, 9 (1), 985 (2018)

22. A. Kosyakov, U. Svit, S. Seymour, S. Beamer, System Engineering. Principles and practice (DMK Press, 2014)

23. I. Abramov, T. Poznakhirko, A. Sergeev, MATECWebConf, 86, 15 (2016) 